\title{
Feto-maternal outcome of pregnancies diagnosed as hypothyroidism after 28 weeks of gestation, at a tertiary hospital
}

\author{
Asha Garg ${ }^{1}$, Sham Sunder Goyal ${ }^{2 *}$, Mini Bedi ${ }^{1}$, Muskan ${ }^{1}$
}

\begin{abstract}
${ }^{1}$ Department of Obstetrics and Gynecology, ${ }^{2}$ Department of Anaesthesiology and Intensive Care, Adesh Institute of Medical Sciences and Research, Bathinda, Punjab, India
\end{abstract}

Received: 23 July 2021

Revised: 07 October 2021

Accepted: 08 October 2021

\section{*Correspondence:}

Dr. Sham Sunder Goyal,

E-mail: drshamgoyal@yahoo.co.in

Copyright: ( ) the author(s), publisher and licensee Medip Academy. This is an open-access article distributed under the terms of the Creative Commons Attribution Non-Commercial License, which permits unrestricted non-commercial use, distribution, and reproduction in any medium, provided the original work is properly cited.

\begin{abstract}
Background: The most frequent thyroid alteration observed in pregnancy is hypothyroidism with subclinical hypothyroidism being more common than overt hypothyroidism. Women with thyroid dysfunction both overt and subclinical are at increased risk of pregnancy-related complications. In present study we assessed feto-maternal outcome of pregnancies in whom hypothyroidism was diagnosed after 28 weeks of gestation.

Methods: This study was conducted in the department of obstetrics and gynaecology, Adesh institute of medical sciences and research Medical College, Bathinda. The present study was of prospective, observational design, conducted in pregnant women with more than 28 weeks pregnancy, first time diagnosed as hypothyroid (TSH>3.0 mIU/l).

Results: In present study total 37 patients completed study protocol, 6 patients were delivered at other hospital. Most patients were less than 20 years (32\%), nulliparous (68\%). 19\% patients delivered preterm either due to spontaneous labour or labour induction for obstetric reason. $62 \%$ patients delivered vaginally, $35 \%$ underwent LSCS. In present study maternal complications such as preterm labour (24\%), hypertensive disorders of pregnancy (22\%), oligohydramnios (16\%), overt/gestational diabetes mellitus $(8 \%)$ and post-partum haemorrhage (5\%) were noted. 2.5 $3.4 \mathrm{~kg}$ birth weight was most common group (65\%). Total $16 \%$ babies required neonatal resuscitation. Babies requiring neonatal resuscitation were admitted in NICU for observation and for any further management. Neonatal jaundice was noted in $30 \%$ babies. Total $22 \%$ babies needed NICU admission. We noted early neonatal death in one baby. No maternal mortality was noted.

Conclusions: Treatment of maternal hypothyroidism is essential, because adverse outcomes for both mother and baby are greatly reduced, if not eliminated, when patients are treated.
\end{abstract}

Keywords: Feto-maternal outcome, Hypothyroidism in pregnancy, Thyroxine, TSH

\section{INTRODUCTION}

Hypothyroidism is a condition characterized by insufficient production of thyroid hormone by the thyroid gland (primary), by the decrease of the pituitary (secondary), or hypothalamic (tertiary) stimulus. ${ }^{1}$ Both subclinical and overt hypothyroidism though often preexists before conception but can sometimes develop during pregnancy. The most frequent thyroid alteration observed in pregnancy is hypothyroidism with subclinical hypothyroidism being more common than overt hypothyroidism..$^{2,3}$

Pregnancy is associated with profound modifications in the regulation of thyroid function. These changes are the result of various factors like an increase of thyroxinebinding globulin (TBG) due to elevated estrogen and human chorionic gonadotropin (hCG), increased renal losses of iodine due to increased glomerular filtration rate, modifications in the peripheral metabolism of maternal 
thyroid hormones, and modification in iodine transfer to the placenta. ${ }^{4}$

Women with thyroid dysfunction both overt and subclinical are at increased risk of pregnancy-related complications such as threatened abortion, preeclampsia, preterm labor, placental abruption, and postpartum hemorrhage. Fetal complications include low-birth-weight babies, first trimester spontaneous abortions, preterm delivery, fetal or neonatal hyperthyroidism, intrauterine growth retardation, high rates of still birth and neonatal deaths, neonatal hyperbilirubinemia, higher incidence of neonatal hypothyroidism, and increased perinatal mortality. ${ }^{5,6}$

In present study we assessed feto-maternal outcome of pregnancies in whom hypothyroidism was diagnosed after 28 weeks of gestation.

\section{METHODS}

This study was conducted in the department of Obstetrics and Gynecology, Adesh institute of medical sciences and research Medical College, Bathinda. The present study was of prospective, observational design. The study duration was from March 2021 to July 2021. Study approval was obtained from institutional ethical committee.

Patients diagnosed as hypothyroid (TSH>3.0 mIU/1) first time after 28 weeks pregnancy coming to antenatal OPD for antenatal check-up or admitted in antenatal ward for any cause was considered for this study.

\section{Inclusion criteria}

Pregnant women with more than 28 weeks pregnancy, diagnosed as hypothyroid (TSH>3.0 mIU/l), willing to participate and deliver at our hospital

\section{Exclusion criteria}

Diagnosed as hypothyroid before 28 weeks, already receiving thyroid supplementation, pregnant women with any medical illness or any pregnancy related complications like gestational diabetes, hypertension, preeclampsia, bad obstetric history etc., known case of obstetric high-risk factor in present pregnancy (IUGR, placenta previa, oligo/polyhydramnios), known fetal anomaly, not willing to participate, follow up.

Study was explained to patients and a written informed consent was taken for participation and follow-up. Demographic details and history (symptoms, obstetric, medical, surgical) was noted. A thorough general physical examination and obstetric examination were carried out. Investigations reports (laboratory, radiological) present with patient were noted. Details related to duration of hypothyroidism and treatment history were also collected.
Patients were advised regular follow up. During follow up details were noted and if required laboratory or radiological investigations were advised. Thyroid function tests were repeated every 6 weeks, if abnormal report is noted then with consultation of physician thyroxine dose was adjusted and TFT's repeated at 3 weeks.

At 40 weeks of gestation admission was advised if patients do not delivered till that time. Depending on obstetric factors management (induction, mode of delivery) was decided by senior obstetrician. Labour was monitored by partograph. All deliveries were attended by neonatologist and newborn were assessed immediately after delivery. Follow up was kept for 7 days postpartum.

Maternal outcomes studied were preterm delivery, gestational hypertension, gestational diabetes, mode of delivery and postpartum haemorrhage. Fetal parameters such as prematurity, low birth weight, need for neonatal resuscitation, NICU admission were studied.

All details were entered in Microsoft excel sheet and statistical analysis was done using descriptive statistics.

\section{RESULTS}

In present study total 37 patients completed study protocol, 6 patients were delivered at other hospital. Most patients were less than 20 years (32\%), nulliparous (68\%). 19\% patients delivered preterm either due to spontaneous labour or labour induction for obstetric reason. $62 \%$ patients delivered vaginally, $35 \%$ underwent LSCS (Table 1).

Table 1: General characteristics.

\begin{tabular}{|lll|}
\hline Characteristic & No. of patients & Percentage \\
\hline Age (in years) & & \\
\hline$<20$ & 12 & 32 \\
\hline $21-25$ & 7 & 19 \\
\hline $26-30$ & 11 & 30 \\
\hline $31-35$ & 5 & 14 \\
\hline$>35$ & 2 & 5 \\
\hline Parity & & \\
\hline 0 & 25 & 68 \\
\hline 1 & 7 & 19 \\
\hline 2 or more & 5 & 14 \\
\hline Gestation at delivery & \\
\hline Preterm & 7 & 19 \\
\hline Term & 30 & 81 \\
\hline Onset of labour & & \\
\hline Spontaneous & 27 & 73 \\
\hline Induced & 6 & 16 \\
\hline Elective LSCS & 4 & 11 \\
\hline Mode of delivery & & 62 \\
\hline Vaginal & 23 & 35 \\
\hline LSCS & 13 & 3 \\
\hline Instrumental & 1 & \\
\hline
\end{tabular}


In present study maternal complications such as preterm labour (24\%), hypertensive disorders of pregnancy (22\%), oligohydramnios $(16 \%)$, overt/gestational diabetes mellites $(8 \%)$ and post-partum hemorrhage $(5 \%)$ were noted (Table 2).

Table 2: Maternal complications/high risk factors.

\begin{tabular}{|lll|}
\hline Complications & $\begin{array}{l}\text { No. of } \\
\text { patients }\end{array}$ & Percentage \\
\hline Haemoglobin <9 gm \% & 18 & 49 \\
\hline LSCS & 13 & 35 \\
\hline Preterm labour & 9 & 24 \\
\hline $\begin{array}{l}\text { Hypertensive disorders of } \\
\text { pregnancy }\end{array}$ & 8 & 22 \\
\hline $\begin{array}{l}\text { Oligohydramnios } \\
\text { Overt/gestational diabetes } \\
\text { mellites }\end{array}$ & 6 & 16 \\
\hline Post-partum hemorrhage & 2 & 8 \\
\hline
\end{tabular}

2.5-3.4 kg birth weight was most common group $(65 \%)$. Total $16 \%$ babies required neonatal resuscitation. Babies requiring neonatal resuscitation were admitted in NICU for observation and for any further management. Neonatal jaundice was noted in $30 \%$ babies. Total $22 \%$ babies needed NICU admission during study period. Majority of them were birth weight less than $2000 \mathrm{gm}$, meconium aspiration, cord looped around neck etc. We noted early neonatal death in 1 baby. No maternal mortality was noted. (Table 3).

Table 3: Perinatal outcome measures.

\begin{tabular}{|lll|}
\hline Outcome measure & $\begin{array}{l}\text { No. of } \\
\text { patients }\end{array}$ & Percentage \\
\hline Birth weight & \multicolumn{2}{|l|}{} \\
\hline $1.5-2.4 \mathrm{~kg}$ & 10 & 27 \\
\hline $2.5-3.4 \mathrm{~kg}$ & 24 & 65 \\
\hline $3.5-4.4 \mathrm{~kg}$ & 3 & 8 \\
\hline Meconium aspiration & 8 & 22 \\
\hline APGAR $\leq 7$ at 1 minute & 5 & 14 \\
\hline APGAR $\leq 7$ at 5 minutes & 2 & 5 \\
\hline $\begin{array}{l}\text { Required neonatal } \\
\text { resuscitation }\end{array}$ & 6 & 16 \\
\hline $\begin{array}{l}\text { Hyperbilirubinemia } \\
\text { (neonatal jaundice) }\end{array}$ & 11 & 30 \\
\hline Admission to NICU & 8 & 22 \\
\hline Neonatal death & 1 & 3 \\
\hline
\end{tabular}

\section{DISCUSSION}

Women who had adequate iodine intake before and during pregnancy have adequate iodine stores and therefore have no difficulty in adapting to the increased demands. However, inadequate stores are gradually depleted during pregnancy, leading to deficiency. This deficiency may lead to fetal and maternal goitre and increased rates of miscarriage, stillbirth, and perinatal and infant mortality. ${ }^{7}$
There can be a varied presentation of hypothyroidism in women during pregnancy. Many of the symptoms and signs of hypothyroidism can overlap with pregnancy, like lethargy weakness, muscle cramps, constipation, hair loss etc., Thus it is difficult to rely on symptoms to make a diagnosis of hypothyroidism in pregnancy. ${ }^{8}$

TSH is the most reliable test for diagnosing hypothyroidism but pregnancy presents a challenge for establishing reliable reference ranges and cutoffs. The recommended reference ranges are 0.1-2.5 $\mathrm{mIU} / \mathrm{l}$ in the first trimester, $0.2-3.0 \mathrm{mIU} / \mathrm{l}$ in the second trimester, and 0.3-3.0 mIU/1 in the third trimester. ${ }^{10}$ Depending on the free $\mathrm{T}_{4}$ levels, it is further classified as overt hypothyroidism $\left(\mathrm{OH}\right.$; free $\mathrm{T}_{4}$ levels decreased) or subclinical hypothyroidism ( $\mathrm{SCH}$; normal $\mathrm{fT}_{4}$ levels). ${ }^{10}$

In a more study, Sahu et al have done thyroid function during second trimester in high-risk pregnant women and reported that prevalence of thyroid disorders, especially overt and subclinical hypothyroidism, was $6.47 \% .^{11}$

Ajmani et al, noted that adverse maternal effects in overt hypothyroidism included preeclampsia (16.6 versus $7.8 \%$ ) and placental abruption (16.6 versus $0.8 \%) .{ }^{12}$ Adverse fetal outcomes in overt hypothyroidism included spontaneous abortion (16.6 versus $2.39 \%$ ), preterm birth (33.3 versus $5.8 \%$ ), low birth weight (50 versus $12.11 \%$ ), intrauterine growth retardation ( 25 versus $4.9 \%$ ), and fetal death (16.6 versus $1.7 \%$ ) as compared to the euthyroid women. In same study, authors noted that subclinical hypothyroidism was associated with preeclampsia $(22.3$ versus $7.8 \%$ ) as compared to the euthyroid patients. Adverse fetal outcomes in subclinical hypothyroidism included spontaneous abortion (5.5 versus $2.39 \%$ ), preterm delivery (11.2 versus $5.8 \%$ ), low birth weight ( 25 versus $12.11 \%$ ), and intrauterine growth retardation (8.4 versus $4.9 \%$ ) as compared to the euthyroid women.

Sreelatha et al studied 96 cases as subclinical hypothyroidism in pregnancy, noted various maternal and fetal complications as abortions $(2.1 \%)$, anaemia $(4.20 \%)$, PIH (14.7\%), GDM (4.2\%), preterm labour $(3.1 \%)$, oligohydramnios (16.67\%), LSCS (22.9\%), PPH (6.3\%), LBW (21.9\%), hyperbilirubinemia (9.4\%), NICU admission (14.6\%). ${ }^{13}$ Similar findings were noted in present study.

Nirmala et al noted that hypothyroidism was associated with 3.6 times higher risk of developing threatened abortion and 3.8 times higher risk of developing gestational hypertension $(\mathrm{p}=0.001) .{ }^{14}$ Rate of caesarean section $(51.3 \%)$ and postpartum haemorrhage $(12.8 \%)$ were higher among cases. They concluded that hypothyroid mothers, in spite of thyroid replacement therapy, are at significantly higher risk of obstetric complications.

Universal screening has not been recommended till now in any country due to paucity of data and most of the 
available guidelines recommend screening of high-risk pregnant women. Government of India also recommends screening of high-risk pregnant women (mothers residing iodine deficiency area, obesity, symptoms of thyroid dysfunction or presence of goitre, positive family history, bad obstetric history, previous recurrent miscarriages, preterm delivery, intrauterine demise, preeclampsiaeclampsia, abruptio placentae, treatment with amiodarone or lithium) for thyroid disorders. ${ }^{15}$

In view of potential adverse outcomes associated with maternal thyroid disorders and obvious benefits of treatment, routine thyroid function screening in all pregnant women is recommended. In hypothyroid patients supplementation should be instituted early because much fetal development occurs in the first trimester.

\section{CONCLUSION}

Subclinical hypothyroidism remains frequently unrecognized unless screening programme are initiated during early pregnancy. Treatment of maternal hypothyroidism is essential, because adverse outcomes for both mother and baby are greatly reduced, if not eliminated, when patients are treated.

\section{Funding: No funding sources}

Conflict of interest: None declared

Ethical approval: The study was approved by the Institutional Ethics Committee

\section{REFERENCES}

1. Brenta G, Vaisman M, Sgarbi JA, Bergoglio LM, Andrada NC, Bravo PP, et al. Clinical practice guidelines for the management of hypothyroidism. Arq Bras Endocrinol Metab. 2013;57:265-91.

2. Alexander EK, Pearce EN, Brent GA, Brown RS, Chen H, Dosiou C, et al. Guidelines of the American Thyroid Association for the diagnosis and management of thyroid disease during pregnancy and the postpartum. Thyroid. 2017;27:315-89.

3. Teng W, Shan Z, Patil-Sisodia K, Cooper DS. Hypothyroidism in pregnancy. Lancet Diabetes Endocrinol. 2013;1:228-37.

4. Negro R, Formoso G, Mangieri T, Pezzarossa A, Dazzi D, Hassan H. Levothyroxine treatment in euthyroid pregnant women with autoimmune thyroid disease: effects on obstetrical complications. J Clin Endocrinol Metab. 2006;91:2587-91.

5. So LB, Mandel SJ. Thyroid disorders during pregnancy. Endocrinol Metab Clin North Am. 2006;35:117-36.
6. Casey BM, Dashe JS, Wells CE, McIntire DD, Byrd W, Leveno KJ, et al. Subclinical hypothyroidism and pregnancy outcomes. Obstet Gynecol. 2005;105:23945.

7. Andersen S, Karmisholt J, Pedersen KM, Laurberg P. Reliability of studies of iodine intake and recommendations for number of samples in groups and in individuals. Br J Nutr. 2008;99:813-8.

8. Dharmalingam M, Kalra P, Mittal R, Jayakumar RV (eds). Thyroid diseases during pregnancy, Indian Thyroid Society, Clinical Manual of Thyroid Disorders, 1st edition, New Delhi, ReedElsevier India 2012;222-23.

9. Lambert-Messerlian G, McClain M, Haddow JE, Palomaki GE, Canick JA, Cleary-Goldman J, et al. First-and second -trimester thyroid hormone reference data in pregnant women: A FaSTER research Consortium study. Am J Obstet Gynecol. 2008;199(1):62-e1.

10. Stagnaro-Green A, Abalovich M, Alexander E, Azizi F, Mestman J, Negro R, et al. Guidelines of the American Thyroid Association for the diagnosis and management of thyroid disease during pregnancy and postpartum. Thyroid. 2011;21(10):1081-125.

11. Sahu MT, Das V, Mittal S, Agarwal A, Sahu M. Overt and subclinical thyroid dysfunction among Indian pregnant women and its effect on maternal and fetal outcome. Arch Gynecol Obstet. 2010;281:215-20.

12. Ajmani SN, Aggarwal D, Bhatia P, Sharma M, Sarabhai V, Paul M. Prevalence of overt and subclinical thyroid dysfunction among pregnant women and its effect on maternal and fetal outcome. J Obstet Gynaecol India. 2014;64(2):105-10.

13. Sreelatha S, Nadagoudar S, Devi AL. The study of maternal and fetal outcome in pregnant women with thyroid disorders. Int J Reprod Contracept Obstet Gynecol 2017;6:3507-13.

14. Nirmala C, Jayakumari C, Rajasekharan C, Nandini VR. Maternal outcome of hypothyroidism in pregnancy- a South Indian perspect. Am J Clin Med Res. 2014;2(2):47-50.

15. National Guidelines for Screening of Hypothyroidism during Pregnancy, Maternal Health Division Ministry of Health and Family Welfare, Government of India, December 2014. Available from: http://www.nrhmorissa.gov.in/writereaddata/Upload/ Documents/National_Guidelines_for_Screening_of_ Hypothyroidism_during_Pregnancy.pdf. Accessed on 11 February 2021.

Cite this article as: Garg A, Goyal SS, Bedi M, Muskan. Feto-maternal outcome of pregnancies diagnosed as hypothyroidism after 28 weeks of gestation, at a tertiary hospital. Int J Reprod Contracept Obstet Gynecol 2021;10:4136-9. 